Agr. Biol. Chem., 38 (8), 1415 1421, 1974

\title{
Isolation and Properties of Carbohydrate Rich Fraction of Wheat Gluten ${ }^{\dagger}$
}

\author{
Yoshiyuki InOuYe, Tatsuro Ito, Takeyoshi Nakahara, Akihiko FukudA, \\ Shigehiro HIRANo and Isao MORISHIMA \\ Department of Agricultural Chemistry, Faculty of Agriculture, \\ Tottori University, Tottori
}

Received September 10, 1973

\begin{abstract}
Two carbohydrate rich fractions A and B were isolated from wheat gluten. Fraction B contained more lipid than fraction A. Lipid portion of fraction B consisted mainly of glycolipid and was fractionated into five fractions by thin-layer chromatography. The two main fractions were extracted and determined to be galactolipid and glucolipid, respectively, by the analyses of fatty acid and sugar components by gas chromatography. Defatted fraction A was assumed to consist of glycoprotein. After complete pronase digestion of defatted fraction A, the remaining glycopeptide moiety was isolated by column chromatography on DEAEcellulose followed by gel filtration through Sephadex G-25. The amino acid and sugar components of the glycopeptide were investigated.
\end{abstract}

Wheat flour is generally fractionated into gluten, starch and water solubles. Gluten is divided into some protein fractions such as gliadin and glutenin. ${ }^{1)}$ Gluten has been reported to contain $5 \sim 10 \%$ of $\operatorname{lipid}^{1 \sim 31}$ and $0.66 \%$ of pentosan ${ }^{4 !}$ as minor components other than protein. Although starch is the main component of the carbohydrates of wheat flour, hemicellulose, pentosan and glycoprotein are known to be included in the flour. Many works have been reported on these components, but only a few have been done on the carbohydrate in gluten. ${ }^{4 \sim 6)}$

In this work we isolated two carbohydrate rich fractions from gluten, one of which contained more lipid than the other. Many works have been reported on lipids and glycolipids in wheat flour, ${ }^{7 \sim 15)}$ and we also worked on the characterization of the fatty acid and sugar components of glycolipids in the carbohydrate rich fractions. In this paper we present, furthermore, the isolation and characterization of a component consisting of sugar and protein, together with the isolation of glycopeptide by enzymatic degradation of the com-

$\uparrow$ This report was presented at the Annual Meeting of the Agricultural Chemical Society of Japan, Tokyo, April 1973. ponent.

\section{MATERIALS AND METHODS}

Flours. The flours used in this experiment were laboratory-milled from Canada Western No. 1, Dark Hard Winter, Western White, Aoba, and Norin No. 61. The protein contents of the respective flours were 12.7, $12.5,7.5,9.9$, and $8.4 \%$.

Preparation of gluten. To $100 \mathrm{~g}$ of flour was added water of a volume equivalent to the water absorbing capacity of the respective flour, and the mixture was kneaded to make a dough. The water absortption capacities of Canada Western No. 1, Dark Hard Winter, Western White, Aoba, and Norin No. 61 as determined with Brabender Farinograph, were 65.0, 63.3, $48.0,54.2$, and $51.5 \%$, respectively. The dough was wrapped with wet gauze and kept at $24^{\circ} \mathrm{C}$ for $30 \mathrm{~min}$. To the dough was added a small amount of water, and then starch and water solubles were washed out by kneading the dough. The washing was repeated until gluten fraction did not react with iodine-potassium iodide solution. The resultant wet gluten was divided into small pieces and lyophylized.

Analytical methods. Total sugar was determined by the anthrone method ${ }^{16)}$ or the phenol-sulfuric acid method. ${ }^{17)}$ Reducing sugar was determined by the method of Somogyi-Nelson ${ }^{18,191}$ using D-glucose as a standard. Gluten was hydrolyzed with $2 \mathrm{~N} \mathrm{HCl}$ at $100^{\circ} \mathrm{C}$ for $16 \mathrm{hr}$ for the determination. These conditions were set up on the basis of the results of preliminary 
experiments.

Protein was calculated by multiplying $\mathrm{N}$ value determined according to the method of Folin ${ }^{201}$ by a factor of 5.7. In column chromatography, protein concentration in eluate was determined by reading optical density at $280 \mathrm{~nm}$ or by the method of Shibata. ${ }^{211}$ Amino acid was determined according to the procedure of Stein-Moore, ${ }^{22 !}$ using L-glutamic acid as a standard. The amino acid composition of protein or peptide was analyzed with an automatic amino acid analyzer (Hitachi model KLA-2).

Lipid was determined by the method of Fukuba et al. ${ }^{231}$ Hexosamine was determined by the method of Elson-Morgan. ${ }^{241}$ Phosphorus was determined by the method of Allen. ${ }^{26}$

Thin-layer chromatography. ${ }^{26)}$ The lipids of carbohydrate rich fraction $\mathrm{B}$ were extracted with chloroform-methanol $(2: 1 \mathrm{v} / \mathrm{v})$, and the extracts were submitted to thin-layer chromatography. It was carried out with Silica-layer $\mathbf{G}$ (Nakarai Chemicals $\mathrm{Co}$.) plates of $0.25 \mathrm{~mm}$ thickness, which were developed with a solvent system of chloroform-methanol-acetic acidwater $(100: 20: 12: 5 \mathrm{v} / \mathrm{v})$. Spots were detected by spraying the following color reagents; $0.2 \%$ ninhydrin in butanol-acetic acid, ${ }^{27}$ Dittmer's reagent, ${ }^{28}$ । $0.2 \%$ $2^{\prime}, 7^{\prime}$-dichlorofluorescein in ethanol, ${ }^{29}$ i Molisch's reagent, ${ }^{30)}$ and $5 \%$ phosphomolybdic acid in ethanol. ${ }^{311}$

\section{Gas chromatography}

1) Glycolipids. The gas chromatography of fatty acids was carried out using a Shimadzu Gas Chromatograph Model GC-5A equipped with a hydrogen flame ionization detector, connected with a stainless steel column of $3 \mathrm{~mm}$ (i.d.) $\times 3 \mathrm{~m}$ at a $30 \mathrm{ml}$ per minute flow rate of nitrogen gas, column packing of $15 \%$ DEGS on Shimalite W, 60 80 mesh, and column temperature $190^{\circ} \mathrm{C}$. The gas chromatography of carbohydrates was carried out with a column packing of $5 \%$ Ucon LB 550X on Shimalite W, $60 \sim 80 \mathrm{mesh}$, and column temperature $170^{\circ} \mathrm{C}$. Other conditions were the same as described above.

2) Carbohydrate rich fraction $A$. It was hydrolyzed with $2 \mathrm{~N} \mathrm{HCl}$ at $105^{\circ} \mathrm{C}$ for $4 \mathrm{hr}$ and the hydrolyzate was deionized with Amberlite IR-120 and IRA410 , evaporated to dryness, and then trimethylsilylated. $^{32)}$ The trimethylsilylated sugars were analyzed with a hydrogen flame ionization detector, connected with a glass column of $3 \mathrm{~mm}$ (i.d.) $\times 2 \mathrm{~m}$, at a $50 \mathrm{ml}$ per minute flow rate of nitrogen gas, with column packing of $2 \sim 4 \%$ Apiezon-L on Chromosorb G, $80 \sim 100$ mesh, column temperature being $180^{\circ} \mathrm{C}$.

3) Glycopeptide. The glycopeptide which was prepared from defatted carbohydrate rich fraction $\mathrm{A}$, was hydrolyzed with $2 \mathrm{~N} \mathrm{HCl}$ at $105^{\circ} \mathrm{C}$ for $4 \mathrm{hr}$ and the hydrolyzate was deionized with Amberlite IR-120 and
IRA-410, evaporated to dryness, and then reduced to alditols. ${ }^{331}$ The alditols were analyzed with a hydrogen flame ionization detector, connected with a glass of $3 \mathrm{~mm}$ (i.d.) $\times 2 \mathrm{~m}$, at a $50 \mathrm{ml}$ per minute flow rate of nitrogen gas, with column packing of $0.5 \%$ ethylene glycol adipate on Chromosorb W, $60 \sim 80$ mesh, column temperature being $190^{\circ} \mathrm{C}$.

\section{RESULTS AND DISCUSSION}

\section{Isolation of carbohydrate rich fractions}

Glutens were prepared from various kinds of flours as described in MATERIALS AND METHODS, and carbohydrate in the glutens was analyzed. The yield of lyophylized gluten and the content of carbohydrate in the gluten are shown in Table I.

Table I. The Yields of Gluten from Different Wheat Flours and Carbohydrate Contents of the Glutens

\begin{tabular}{lcc}
\hline \multicolumn{1}{c}{ Wheat flour } & $\begin{array}{c}\text { Dry gluten } \\
\%\end{array}$ & $\begin{array}{c}\text { Carbohydrate } \\
\%\end{array}$ \\
\hline Canada Western No. 1 & 13.3 & 0.94 \\
Dark Hard Winter & 12.4 & 0.85 \\
Western White & 7.5 & 1.15 \\
Aoba & 9.9 & 0.65 \\
Norin No. 61 & 8.4 & 0.56 \\
\hline
\end{tabular}

a) Carbohydrate was determined by anthrone method. ${ }^{16)}$

The isolation of the carbohydrate rich fraction from Canada Western No. 1 flour was carried out as follows. ${ }^{5)}$ To $1 \mathrm{~kg}$ of flour was added $600 \mathrm{ml}$ of water and the mixture was kneaded to make a dough. Starch and water solubles were washed out with tap water by kneading for $15 \sim 20 \mathrm{hr}$. Resultant $450 \mathrm{~g}$ of wet gluten was divided into small pieces and dissolved in 1.5 liters of $0.01 \mathrm{~N}$ lactic acid. Insoluble materials were spun off at 14,000 rpm for $10 \mathrm{~min}$. To the supernatant was added 3 liters of $70 \%$ ethanol and the suspension was stirred for $2 \mathrm{hr}$. The $\mathrm{pH}$ of the suspension was adjusted to 6.4 with $0.01 \mathrm{~N}$ sodium carbonate. After keeping at $5^{\circ} \mathrm{C}$ for $24 \mathrm{hr}$, the precipitate (glutenin) was spun off, and ethanol in the supernatant which contained most of carbohydrates was evaporated under reduced pressure at $40 \sim 50^{\circ} \mathrm{C}$. After keeping 
the solution at $5^{\circ} \mathrm{C}$ for $24 \mathrm{hr}$, the precipitate was collected by centrifugation at $5000 \mathrm{rpm}$ for $20 \mathrm{~min}$, and redissolved in 1 liter of $70 \%$ ethanol. During the standing of the solution at $5^{\circ} \mathrm{C}$ for $24 \mathrm{hr}$, reappeared a precipitate which was rich in carbohydrates. The precipitate was collected by centrifugation as above and redissolved in 1 liter of $70 \%$ ethanol. The redissolution and reprecipitation were repeated additionally twice. The finally obtained precipitate was collected by centrifugation at $5000 \mathrm{rpm}$ for $20 \mathrm{~min}$ and washed successively with $70 \%$ ethanol, $99 \%$ ethanol, and ether, and then dried under reduced pressure (fraction A). The yield was 0.85 to $1.8 \mathrm{~g}$. The supernatant was recentrifuged at $15,000 \mathrm{rpm}$ for $30 \mathrm{~min}$, the precipitate was collected, washed and dried as above (fraction B). The yield was 0.25 to $1.3 \mathrm{~g}$. The carbohydrate rich fractions were also prepared from the flours of Dark Hard Winter, Western White, and Norin No. 61. The yield of Fraction A was 0.3 to $5.2 \mathrm{~g}$, and that of fraction $\mathrm{B}$ was 0.2 to $1.7 \mathrm{~g}$ per $\mathrm{kg}$ of flour.

In the preparation of the carbohydrate rich fractions, they were first soluble in $70 \%$ ethanol accompanied with gliadin, but in the next step they became insoluble in $70 \%$ ethanol. The fractions may be loosely linked with gliadin in dough and hence be soluble in aqueous ethanol. They seemed to become insoluble because of a breakdown of the loose linkage to produce artifacts in the course of preparation. The carbohydrate rich fractions, therefore, may function as a part of gliadin for baking or other food chemical properties of flour.

\section{Analysis of carbohydrate rich fractions}

The contents of protein, carbohydrate, and lipid in fractions A and B were determined. The results are shown in Table II. The results indicate that fraction A contains more protein, and less reducing sugar than fraction $B$. The analytical values of defatted fraction $B$ were similar to those of fraction $\mathrm{A}$. The both fractions contained hexosamine and phosphorus.

\section{Lipid of carbohydrate rich fraction}

The lipids of the carbohydrate rich fractions were characterized by their infrared absorption spectra and thin-layer chromatography. In Fig. 1, the infrared absortpion spectra of fractions $A$ and $B$ are shown. In the spectrum of fraction $B$, a specific absorption for lipid at $2900 \mathrm{~cm}^{-1}$ was observed. The same specific absorption for lipid was slightly observed in the spectrum of fraction $A$. The lipids were extracted with chloroform-methanol $(2: 1, v / v)$, and chromatographed on thin-layer precoated with Silica-layer G. From the results shown in Fig. 2, five spots of glycolipids of No. $1,2,3,4$, and 5 which had $R f$ values of $0.42,0.49,0.72,0.85$, and 0.90 , respectively, were observed in both fractions $A$ and $B$. Phospholipid was hardly detected in both fractions. The spots of No. 2 and 3 were scraped off, eluted from Silica-layer G, and hydrolyzed with $5.9 \% \mathrm{HCl}$ in methanol at $100^{\circ} \mathrm{C}$ for $3 \mathrm{hr}$. To the hydrolyzate was

Table II. Analyses of Carbohydrate Rich Fractions A and B

\begin{tabular}{|c|c|c|c|c|c|}
\hline & $\begin{array}{c}\text { Fraction A } \\
\%\end{array}$ & $\begin{array}{c}\text { Fraction B } \\
\%\end{array}$ & $\begin{array}{c}\text { Defatted } \\
\text { fraction } \mathrm{B}^{a \mid} \\
\%\end{array}$ & $\begin{array}{c}\text { Gliadin } \\
\% \\
\end{array}$ & $\begin{array}{c}\text { Glutenin } \\
\% \\
\end{array}$ \\
\hline Nitrogen & 14.4 & 11.6 & 14.1 & 17.0 & 16.5 \\
\hline Protein $(\mathrm{N} \times 5.7)$ & 82.1 & 66.1 & 80.3 & 96.9 & 94.0 \\
\hline Total sugar & 3.2 & 7.2 & 3.9 & 0.10 & 0.22 \\
\hline Reducing sugar & 5.4 & 9.8 & 6.2 & & \\
\hline Hexosamine & 0.22 & 0.26 & & & \\
\hline Phosphorus & 0.23 & 0.26 & & & \\
\hline Lipid & & 4.4 & & & \\
\hline
\end{tabular}

a) Fraction B was defatted with chloroform-methanol $(2: 1 \mathrm{v} / \mathrm{v})$. 


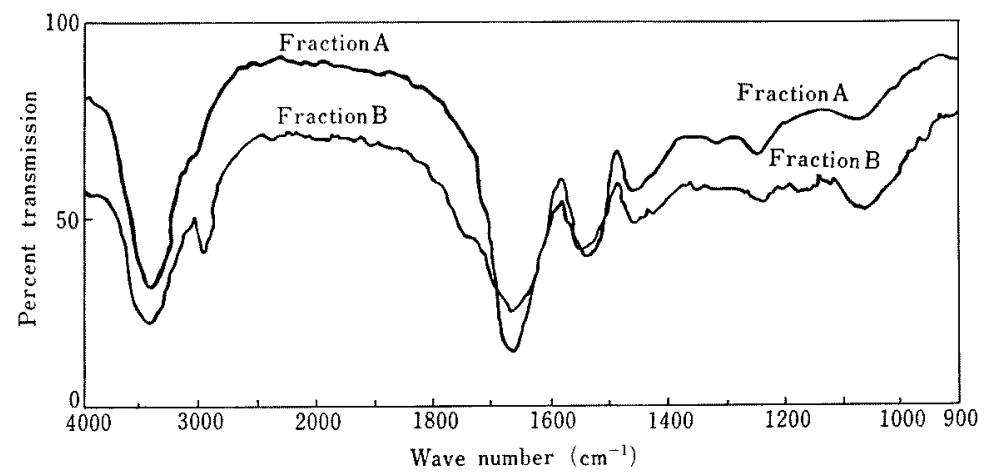

Fig. 1. Infrared Spectra of Carbohydrate Rich Fractions A and B.

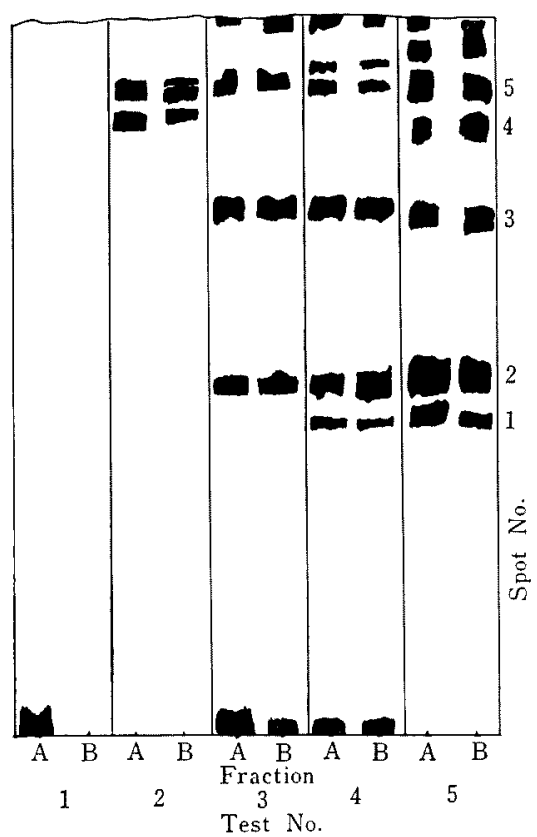

FIG. 2. Thin-Layer Chromatograms of the Lipids of Carbohydrate Rich Fractions A and B.

Color reagents were ninhydrin ${ }^{27}$ for test No. 1, Dit$\operatorname{tmer}^{281}$ for No. 2, dichlorofluorescein ${ }^{29}$ for No. 3, Molisch $^{301}$ for No. 4, and phosphomolybdic acid ${ }^{311}$ for No. 5 .

added petroleum ether and the mixture was shaken vigorously. In this treatment, fatty acids were carried into the petroleum ether layer, and carbohydrate remained in the methanol layer. The latter layer was used for analysis of fatty acid with gas chromatography. Hydrochloric acid was removed from the methanol layer with Amberlite IR-4B, and the solvent was evaporated to give a dry product.
Then the dried sugars were converted into trimethylsilyl derivertives, and analyzed with gas chromatography. The chromatograms of fatty acids and sugars are shown in Figs. 3 and 4, respectively. Palmitic, stearic and oleic acids were detected in spots Nos. 2 and 3 (Fig. 3), and their contents were decreased in that order. In Fig. 4, in spots Nos. 2 and 3 glucose and galactose were detected. The ratio of glucose and galactose was 1:4 in spot No. 2, and 3:1 in spot No. 3. The difference between spots Nos. 2 and 3 is markedly observed in their sugar components. Spots No. 2 and 3 are likely to consist mainly of galactolipid and glucolipid, respectively.

\section{Glycopeptide from carbohydrate rich fraction}

Since sugars and proteins in fraction A or B seemed to be linked with each other to make glycoprotein, an attempt was made to isolate the linkage group as a glycopeptide by enzymatic degradation. Defatted Fraction A (1 g) was suspended in $100 \mathrm{ml}$ of $0.2 \mathrm{M}$ Tris- $\mathrm{HCl}$ buffer, $\mathrm{pH} 7.8$, containing $0.01 \mathrm{M}$ calcium acetate and to this was added $200 \mathrm{mg}$ of Pronase $\mathrm{P}$ (Kaken Chemicals Co.). After incubation at $37^{\circ} \mathrm{C}$ for $120 \mathrm{hr}$, insoluble materials were filtered off. The glycopeptides were precipitated by adding ten volumes of ethanol. The digestion was repeated twice, and to the final reaction mixture was added $5 \%$ of trichloroacetic acid to remove protein. In the next step, trichloroacteic acid was removed from the mixture by ether extraction. ${ }^{3,4}$ The resultant solution was concentrated in vacuo 


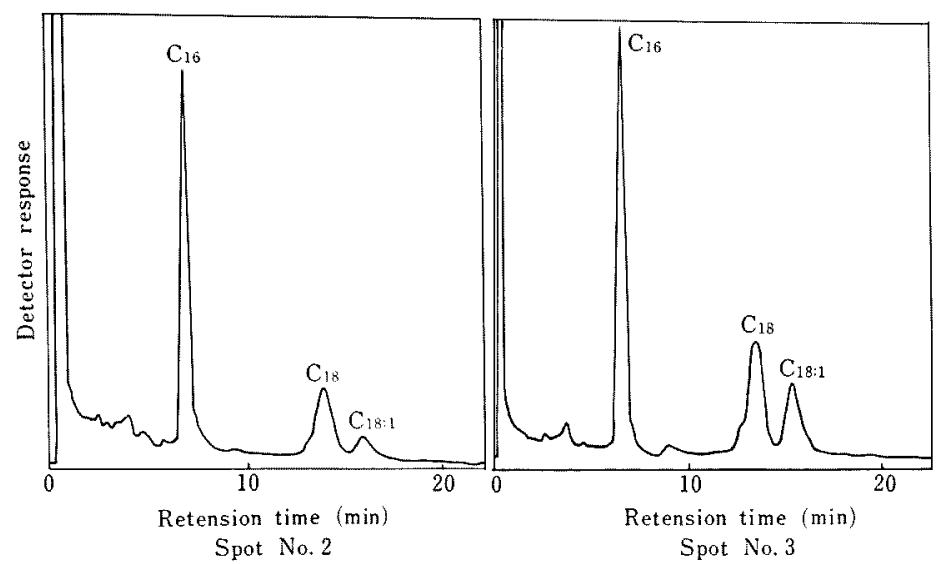

Fig. 3. Gas Chromatograms of the Fatty Acid Components of Glycolipid Spots No. 3 and No. 4.

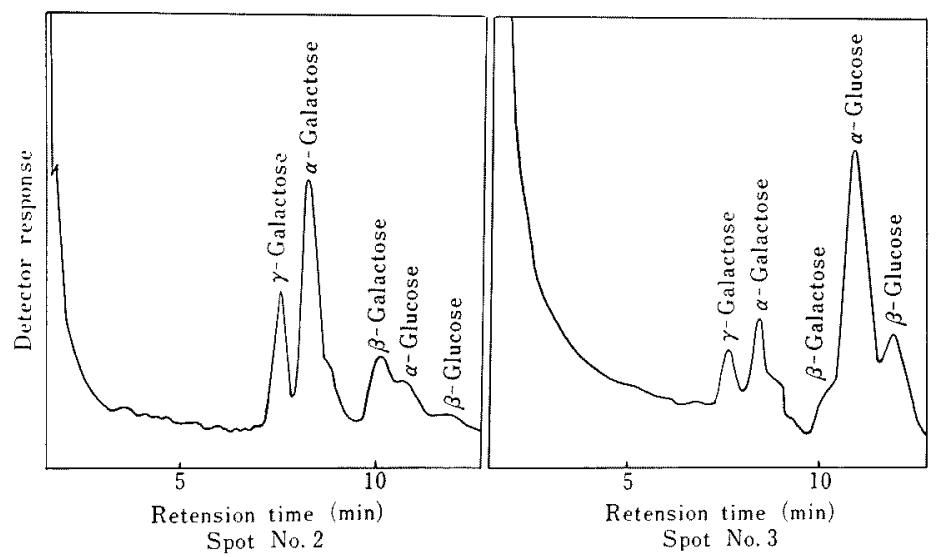

FIG. 4. Gas Chromatograms of the Carbohydrate Components of Glycolipid Spots No. 3 and No. 4.

at $35 \sim 40^{\circ} \mathrm{C}$. The concentrated solution was adsorbed onto a DEAE-cellulose column $(2 \times$ $45 \mathrm{~cm}$ ), and eluted successively with water, $0.1 \mathrm{M}$ sodium biborate, and $0.5 \mathrm{~N} \mathrm{NaOH}$. In the chromatogram shown in Fig. 5, two peaks (fractions Nos. 50 65, and Nos. 100 125) seemingly corresponding to glycopeptide were observed. Fractions Nos. 100 to 125 were collected, concentrated and gel-filtrated through Sephadex G-25. The chromatogram is shown in Fig. 6. The glycopeptide fraction, that is, the fraction in which the peak of sugar overlapped with that of protein was collected, deionized with an ion-exchanger and concentrated. The glycopeptide was precipitated by addition of ethanol. The precipitate was dissolved in water, and reprecipitated with ethanol. After this procedure was repeated three times, the precipitate of glycopeptide was washed with ethanol, ether, and dried. The yield was $0.085 \mathrm{~g}$ from $1 \mathrm{~g}$ of fraction $\mathrm{A}$.

Amino acid and sugar composition of the glycopeptide

The amino acid compositions of gliadin, defatted fraction $\mathrm{A}$, and glycopeptide are summarized in Table III. The amino acid composition of fraction $\mathrm{A}$ is similar to that of gliadin, but a great difference is observed in its higher glycine content.

In the glycopeptide, only five amino acids, proline, glutamic acid, glycine, aspartic acid, and alanine, were detected. Especially high concentrations of proline, glutamic acid, and 


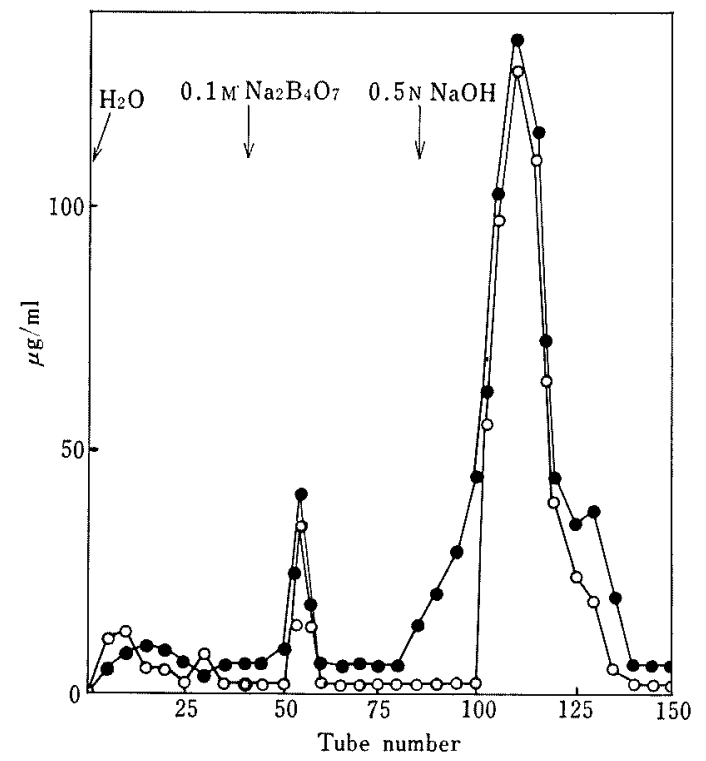

FIG. 5. DEAE-cellulose Chromatography of the Glycoprotein.

Five $\mathrm{ml}$ of digested and concentrated solution were applied to a DEAE-cellulose column $(2 \times 45 \mathrm{~cm})$, and eluted stepwise with distilled water, $0.1 \mathrm{M}$ sodium biborate, and $0.5 \mathrm{~N}$ sodium hydroxide. The flow rate was $15 \mathrm{ml}$ per $\mathrm{hr}$, and each tube contained $10 \mathrm{ml}$ of eluate. Sugar was determined colorimetrically by phenol-sulfuric acid method ${ }^{17}$ and protein was determined by UV absorption method at $280 \mathrm{~nm}$.

$\mathrm{O}-\mathrm{O}$, sugar; $-\boldsymbol{-}$, protein.

Table III. Amino Acid Composition of Gliadin, CaRbohydrate Rich Fraction, and Glycopeptide (moles amino acid per $10^{5} \mathrm{~g}$ )

\begin{tabular}{lrrr}
\hline \multicolumn{1}{c}{ Amino acid } & Gliadin & $\begin{array}{c}\text { Carbo- } \\
\text { hydrate } \\
\text { rich } \\
\text { fraction A }\end{array}$ & $\begin{array}{c}\text { Glyco- } \\
\text { peptide }\end{array}$ \\
\hline Lysine & 4 & 16 & - \\
Histidine & 16 & 16 & - \\
Arginine & 15 & 29 & - \\
Cystine/2 & 12 & 33 & - \\
Aspartic acid & 20 & 27 & 41 \\
Threonine & 14 & 24 & - \\
Serine & 42 & 52 & - \\
Glutamic acid & 382 & 205 & 307 \\
Proline & 120 & 142 & 355 \\
Glycine & 24 & 86 & 170 \\
Alanine & 16 & 37 & 27 \\
Valine & 22 & 24 & - \\
Methionine & 8 & 5 & - \\
Isoleucine & 44 & 32 & - \\
Leucine & 66 & 76 & - \\
Tyrosine & 16 & 23 & - \\
Phenylalanine & 28 & 26 & - \\
Ammonia & 215 & 212 & 304 \\
\hline
\end{tabular}

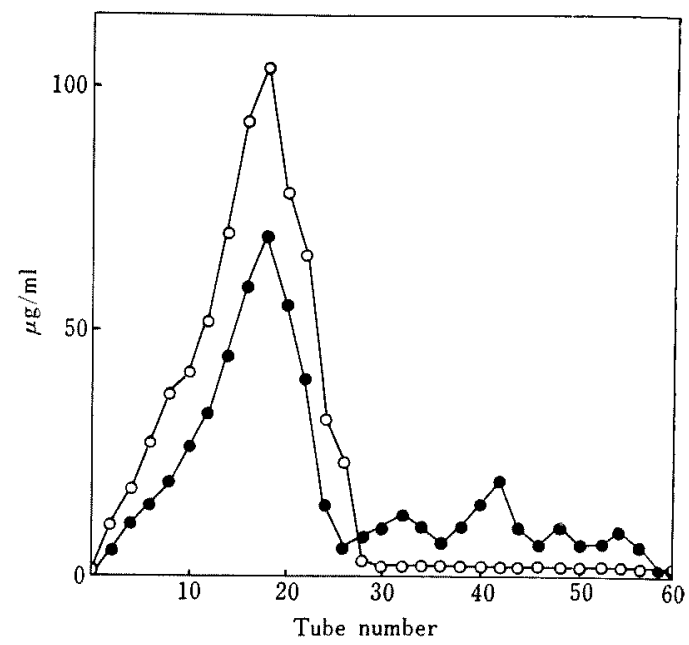

FIG. 6. Gel Filtration of the Glycopeptide through Sephadex G-25.

Fractions of tube numbers 100 to 117 in Fig. 6 were applied to a Sephadex G-25 column $(2 \times 40 \mathrm{~cm})$, and filtered with $0.05 \mathrm{~m}$ sodium acetate buffer at $\mathrm{pH} 6.4$. The flow rate was $15 \mathrm{ml}$ per $\mathrm{hr}$, and each tube contained $10 \mathrm{ml}$ of eluate. Sugar was determined by phenol-sulfuric acid method, ${ }^{171}$ and protein was determined by the method of Shibata. ${ }^{21}$ $\mathrm{O}-\mathrm{O}$, sugar; -0, protein.
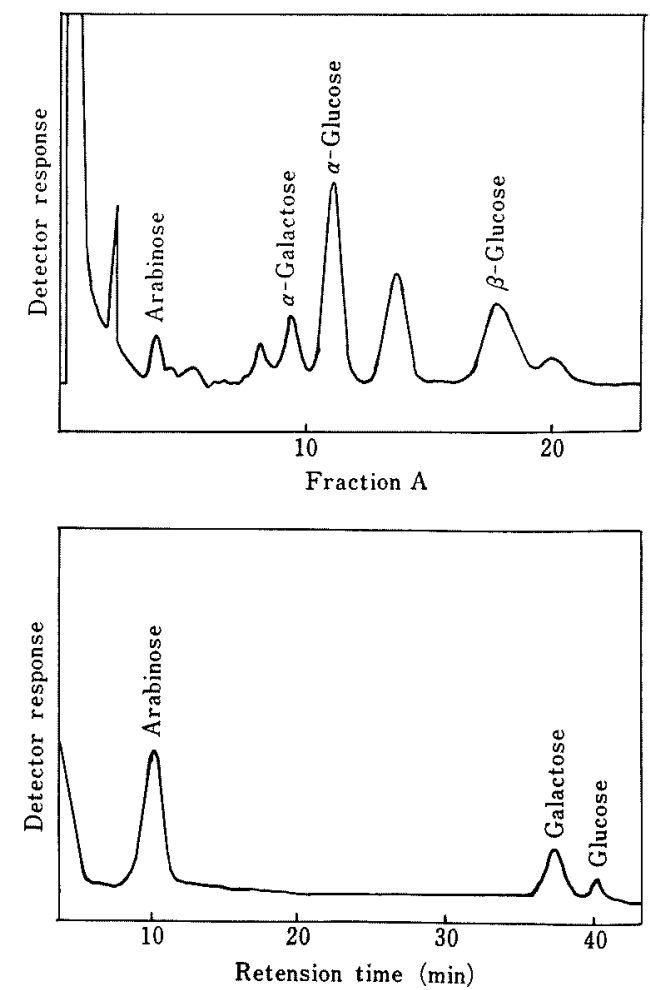

Fig. 7. Gas Chromatographic Analysis of Carbohydrates in Fraction A and Glycopeptide. 
glycine were characteristic. Though some part of glutamic acid or aspartic acid may exist as glutamine or asparagine, it is however, uncertain. The linkage group of sugar and amino acid in the glycopeptide is now under investigation.

The sugar components of fraction $\mathrm{A}$ and glycopeptide were determined by gas chromatography as illustrated in Fig. 7. Fraction A contained glucose, galactose and arabinose. In the glycopeptide, arabinose, galactose and glucose were also detected, and their contents were $38.2,32.3$ and $29.5 \%$, respectively. It is noteworthy that the glycopeptide contains a larger amount of arabinose than fraction $\mathrm{A}$.

Acknowledgement. The authors are greatly indebted to Dr. Taro Hori, professor of Shiga University, for the analysis of lipid, and to Nisshin Flour Milling Co. Ltd., and Dr. Seiichi Nagao for generous gift of wheat flours.

\section{REFERENCES}

1) D. D. Kasarda, C. C. Nimmo and G. O. Kohler, "Wheat, Chemistry and Technology," ed. by Y. Pomeranz, American Association of Cereal Chemists, St. Paul, Minesota, 1971, p. 227.

2) H. S. Olcott and D. K. Mecham, Cereal Chem., 24, 407 (1947).

3) D. B. Dill, ibid., 2, 1 (1925).

4) J. C. Baker, H. K. Parker and M. D. Hize, ibid., 20, 267 (1943).

5) K. Kondo and H. Murayama, J. Chem. Soc. Japan, 54, 351, 386 (1933).

6) L. H. Ford and S. Peat, J. Chem. Soc., 1941, 856.

7) D.K. Mecham and A. Mohammad, Cereal Chem., 32, 405 (1955).

8) J. C. Grosskreutz, ibid., 38, 336 (1961).

9) H. E. Carter, R. A. Hendry, S. Nojima, N. Z. Stanacev and K. Ohno, J. Biol. Chem., 236, 1912 (1961).
10) H. E. Carter, R. A. Hendry and N. Z. Stanacev, J. Lipid Res., 2, 223 (1961).

11) H. E. Carter, R. H. McCluer and E. C. Slifer, $J$. Amer. Chem. Soc., 78, 3735 (1956).

12) H. E. Carter, K. Ohno, S. Nojima, C. L. Tipton and N. Z. Stanacev, J. Lipid Res., 2, 215 (1961).

13) T. A. Clayton, T. A. MacMurray and W. R. Morrison, J. Chromatog., 47, 277 (1970).

14) M. E. McKillican, J. Amer. Oil. Chem. Soc., 4, 554 (1964).

15) D. V. Kyhre, Can. J. Chem., 46, 3071 (1968).

16) Z. Dische, "Methods in Carbohydrate Chemistry" Vol. I, ed. by R. L. Whistler and M. L. Wolfrom, Academic Press Inc., New York, 1962, p. 488.

17) J. E. Hodge and B. T. Hofreiter, "Methods in Carbohydrate Chemistry," Vol. I, ed. by R. L. Whistler and M. L. Wolfrom, Academic Press Inc., New York, 1962, p. 380.

18) M. Somogyi, J. Biol. Chem., 160, 61 (1945); 195, 19 (1952).

19) N. Nelson, ibid., 153, 375 (1944).

20) O. Folin and W. Denis, ibid., 26, 473 (1916).

21) K. Shibata, ibid, , 61, 328 (1967).

22) S. Moore and W. H. Stein, ibid., 211, 907 (1954).

23) H. Fukuba, N. Yamazawa and C. Inagaki, Nippon Nôgeikagaku Kaishi, 28, 59 (1958).

24) B. Schloss, Anal. Chem., 23, 1321 (1951).

25) R. J. L. Allen, Biochem. J., 34, 858 (1940).

26) V. P. Shipski, R. F. Peterson and M. Barclay, ibid., 90, 374 (1964).

27) H. Wagner, L. Horhammer und P. Wolff, Biochem. Z., 334, 175 (1960).

28) J. C. Dittmer and R. L. Lester, J. Lipid Res., 5, 396 (1968).

29) H. K. Mangold, J. Amer. Oil Chem. Soc., 38, 708 (1961).

30) A. W. Devor, Anal. Chem., 24, 1626 (1948).

31) M. Barbier, H. Jager, H. Tobias und E. Wyss, Helv. Chim. Acta, 42, 2440 (1959).

32) C. C. Sweeley, R. Bentley, M. Makita and W. W: Wells, I. Amer. Chem. Soc., 85, 2497 (1963).

33) J. S. Sawardeker, J. H. Sloneker and A. Jeanes, Anal. Chem., 37, 1, 1602 (1965).

34) I. Yamashina and $M$ Makino, J. Biochem., 51, 359 (1962). 